\title{
Finite element modeling of the behavior of polymethyl-methacrylate (PMMA) during high pressure torsion process
}

\author{
Ahmed Drai \\ Mechanical Engineering Department, University of Mascara, 29000, LABAB Laboratory of ENPO, Algeria. \\ draiabmed14@yahoo.fr, http:/ /orcid.org/0000-0001-6091-9519
}

Benaoumeur Aour

Laboratory of Applied Biomechanics And Biomaterials (LABAB), ENP Oran, BP1523 El Mnaour, Oran, 31000, Algeria. benaoumeur.aour@enp-oran.dz,bttp://orcid.org/0000-0002-2345-6790

Naima Belayachi

Université d'Orléans, Laboratoire de Mécanique Gabriel Lamé Polytech Orléans, 45072 Orléans, France. naima.belayachi@univ-orleans.fr, bttp://orcid.org/0000-0002-2345-6791

Abderrahim Talha

Ecole des Hautes Etudes d'Ingénieur (HEI), 13 rue de Toul, 59046 Lille, Lille Mechanics Unit, University of Lille, France abderrahim.talha@hei.fr,.bttp://orcid.org/0000-0003-2345-6792

Noureddine Benseddiq

Lille Mechanics Unit, University of Lille, France

noureddine.benseddiq@univ-lille1.fr, bttp:/ / orcid.org/0000-0003-2345-6793

\begin{abstract}
High Pressure Torsion (HPT) is a highly effective super-plastic deformation process for obtaining nano-materials with high performance mechanical properties. In view of its optimization, it is of paramount importance to evaluate the relations between the behavior of the material under the effects of different processing parameters. In this context, this work aims to highlight the plastic strain distribution in the deformed material as a function of the hydrostatic pressure, the torsion angle and the temperature of the material applied during the process. A typical amorphous polymer (Polymethyl-Methacrylate: PMMA) has been tested. Firstly, in order to identify the material parameters of a phenomenological elasto-viscoplastic model compression tests at different temperatures and strain rates have been carried out. Then, the distributions of the effective plastic strain, the equivalent plastic strain rate and the hydrostatic stress were analyzed using finite elements method. Recommendations on process conditions were
\end{abstract}

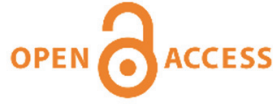

Citation: Drai, A., Aour, B., Belayachi, N., Talha, A., Benseddiq, N., Numerical modeling of polymethyl-methacrylate (PMMA)behavior during high pressure torsion process, Frattura ed Integrità Strutturale, 52 (2020) 181-196.

Received: 20.12.2019

Accepted: 10.02 .2020

Published: 01.04.2020

Copyright: (C) 2020 This is an open access article under the terms of the CC-BY 4.0, which permits unrestricted use, distribution, and reproduction in any medium, provided the original author and source are credited. 
proclaimed at the end of this work according to the obtained numerical results.

KEYwORDS. HPT; Finite Elements; PMMA; Behavior; Plastic strain.

\section{INTRODUCTION}

here have been extensive investigations over the last two decades into the production of bulk ultrafine-grained (UFG) materials through the application of severe plastic deformation (SPD) [1,2]. Recently, SPD techniques have been used in the modification of microstructure. They made possible to produce nano-crystalline (NC) microstructures out of metallic materials [3, 4]. Such SPD methods include High Pressure Torsion (HPT), Equal Channel Angular Pressing (ECAP), Accumulative Roll Bonding (ARB), Multiple Forging, Twist Extrusion (TE) and some others. Among the various SPD techniques, Equal-Channel Angular Pressing (ECAP) and High Pressure Torsion (HPT) are the most common [5]. To date, processing by HPT has proven to be the most effective of all the SPD methods in producing bulk nanostructured materials [6]. Its principle consists in putting a disk between two massive anvils under a simultaneously or successively action of high compression and torsion as shown in Fig. 1.

The occurrence of superplasticity was reported not only after HPT processing of thin disc specimens [7,8], but also using the ring samples [9,10], bulk samples [11,12] as well as after continuous high-pressure torsion extrusion [13]. Different materials have been tested experimentally [14] and theoretically [15] through the application of HPT process such as aluminum alloys [8, 16], nickel [17], copper [15], titanium alloys [3, 18], polymers [19], zirconium [20, 21], Magnesium alloys [22], aluminum-zinc alloys [23], intermetallics [24, 25] and others (see [26, 27]).

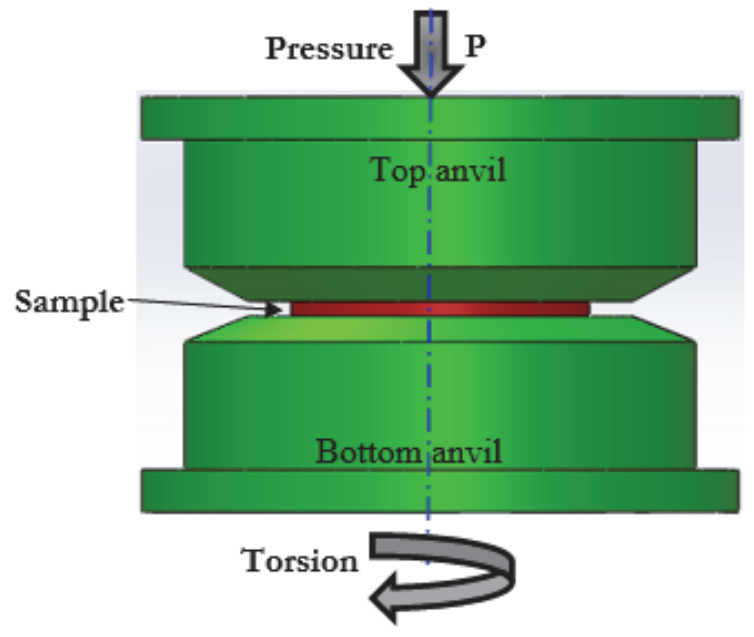

Figure 1: Schematic illustration of HPT process.

In the past, FEM simulations of the SPD processes were performed with the purpose of analysis and optimization of the SPD processing variables and prediction of the mechanical and microstructural characteristics of the SPD processed samples [15]. For example, for HPT, the effects of processing parameters, such as geometries of the disc [28], applied pressure [29], temperature distribution [30,31], rotation rate [31], friction conditions [32], material porosity and properties [32, 33] and slope of the inclined anvil's surface [34] on the plastic strain behavior were reported in the literature extensively.

This work is devoted to study the behavior of polymethyl-methacrylate (PMMA) during HPT process. It is important to note that the behavior of this amorphos polymer is sensitive to the strain rate, temperature, hydrostatic pressure and torsion angle [35]. A three-dimensional finite element analysis has been conducted using hexahedral element with 8-nodes. Our particular attention has been focused on the distribution of the plastic strain in the deformed material as a function of the different parameters of the process, namely, the sequence of the different phases, the hydrostatic pressure, the torsion angle and the temperature of the material during the process. 


\section{CONSTITUTIVE MODELING}

7 o model the PMMA behavior during HPT process, the elasto-viscoplastic model of Perzyna has been used [36]. The material parameters of this model have been identified using compressive tests on PMMA cylindrical specimens at different temperatures and strain rates. The experimental protocol used for this solicitation mode was also presented in details in the next section.

The Perzyna model considers the hypo-elastic relation, and the additive decomposition of the tensor of the strain rates to write [36]:

$$
\dot{\sigma}={ }^{4} \mathrm{H}:\left(\mathrm{D}-\mathrm{D}^{v p}\right)
$$

with $\mathrm{H}$ is the Hooke tensor (tensor of elasticity) given by:

$$
\mathrm{H}=\frac{E}{2(1+v)}\left[\left(\delta_{i k} \delta_{j l}+\delta_{i l} \delta_{j k}\right)+\frac{2 v}{1-2 v} \delta_{i j} \delta_{k l}\right]
$$

where $E$ and $v$ represent respectively the Young's modulus and the Poisson's ratio and $\delta$ is the Kronecker symbol. The viscoplastic deformation rate is given by the rule of normality. Its direction is normal to the surface flow in the stress space $\frac{\partial f}{\partial \sigma}, f$ being the surface flow. By introducing the hypothesis that the function $f$ is independent of the deformations, and supposing the Von Mises criterion [37], the viscoplastic strain is formulated as follows:

$$
\mathrm{D}^{v p}=\gamma \varphi(f) \frac{\partial f}{\partial \sigma}
$$

with $\frac{\partial f}{\partial \sigma}=1$ in the case of a perfectly viscoplastic material.

where $\varphi(f)$ is a function generally chosen as a power function:

$$
\varphi(f)=\left(\frac{\sigma}{\sigma_{0}}-1\right)^{\frac{1}{m}}
$$

Then, we obtain:

$$
\mathrm{D}^{v p}=\gamma\left(\frac{\sigma}{\sigma_{0}}-1\right)^{\frac{1}{m}}
$$

where $m$ and $\gamma$ are respectively the hardening parameter and the viscosity (strain rate sensitivity parameters), $\sigma$ is the flow stress and $\sigma_{0}$ is the static elastic limit. The Perzyna model describes only the sensitivity of the yield stress to the strain rate, then it is necessary to introduce the post yield softening and hardening.

The finite element program used allows us to take into account this post-flow behavior. A multilinear isotropic hardening combined with the Von Mises criterion has been adopted. It should be noted that in this study, we assume that the viscoelastic part of the response does not significantly affect the global results and the pre-yield response is assumed to be linear and elastic.

The behavior in large deformations of viscoplastic solids is described by the constitutive equations, for which analytical solutions are difficult to obtain, even for simplified problems. This model has attracted a lot of attention in the literature because it was validated experimentally in the work of Perzyna [38]. In addition, its simplicity of writing made it easier to 
implement in simulation codes. Peric et al. [39] have used this model in their numerical studies to adapt to large deformations the behavior of materials depending on time and the history of deformation. The work of Van Der Sluis et al. [40, 41] on polycarbonate loaded with elastomer particles has brought an interesting approach based on the Perzyna model and a nonlinear hardening which has shown the efficiency of the use of this models type for polymers.

\section{EXPERIMENTAL PROCEDURE FOR MATERIAL PARAMETERS IDENTIFICATION}

o identify the parameters of the elasto-viscoplastic constitutive law presented in the previous paragraph, we used compression tests at different strain rates and different temperatures conducted on polymethyl-methacrylate (PMMA) samples. Noting that compressive loading, unlike traction, provides (or delays as much as possible) the damage mechanisms.

\section{Material properties}

The material studied (PMMA) was supplied by the Goodfellow ${ }^{\odot}$ company in the form of a cylindrical bar of $8 \mathrm{~mm}$ in diameter and $1000 \mathrm{~mm}$ in long, with a molar mass of the order of $65 \mathrm{~kg}^{-\mathrm{mol}^{-1}}$. The glass transition temperature is about $120^{\circ} \mathrm{C}$. The mechanical properties of this material are shown in Tab. 1.

\begin{tabular}{cc}
\hline \multicolumn{2}{c}{ Mechanical properties of PMMA } \\
Density $\left(\mathrm{g} \mathrm{cm}^{-3}\right)$ & 1.19 \\
Coefficient of friction & $0.25-0.4$ \\
Hardness - Rockwell & $92-100$ \\
Impact resistance - Izod $\left(\mathrm{J} \mathrm{m}^{-1}\right)$ & $16-32$ \\
Poisson coefficient & $0.35-0.4$ \\
Elongation at fracture $(\%)$ & $2.5-4$ \\
Traction module $(\mathrm{GPa})$ & $2.4-3.3$ \\
Tensile strength $(\mathrm{MPa})$ & 80 \\
\hline Table 1: Mechanical properties of the studied polymer (PMMA).
\end{tabular}

\section{Description of the mechanical test}

In order to determine the three parameters $\left(\sigma_{0}, \mathrm{~m}, \gamma\right)$ of the elasto-viscoplastic model, the PMMA sample was tested at strain rates ranging from $10^{-5} \mathrm{~s}^{-1}$ to $10^{-2} \mathrm{~s}^{-1}$ at a room temperature $\left(25^{\circ} \mathrm{C}\right)$ and high temperatures $\left(40^{\circ} \mathrm{C}, 60^{\circ} \mathrm{C}\right.$ and $\left.80^{\circ} \mathrm{C}\right)$. The uniaxial compression tests are performed on an Instron 5867 tensile/compression machine using a $10 \mathrm{KN}$ cell to measure the applied force. The acquisition of experimental data in stresses and strains at each moment during the test was recorded using the Bluehill software. The displacement of the upper plate is controlled with a translational speed of the crossbar calculated from the speed of deformation. All samples were compressed up to $40 \%$ of deformation using two parallel compression trays.

To study the dependence of the polymer behavior at a high temperature, we used a thermal enclosure allowing tests with temperatures up to $250^{\circ} \mathrm{C}$. To ensure the homogeneity of the temperature in the specimen, it was maintained for about 15 minutes at the desired temperature before starting the test. The upper end of the sample is left free during the heating phase to allow thermal expansion to take place freely. To investigate the influence of the temperature increase on the stress-strain curve, the PMMA sample was tested at temperatures ranging from $25^{\circ} \mathrm{C}$ to $100^{\circ} \mathrm{C}$ at a constant strain rate.

From the registration of the cross-bar displacement and the measurement of the force $\mathrm{F}$ during the test, the nominal strainstress curves are deduced using the Bluehill software integrated in the electromechanical testing machine. To make the necessary transformations in true quantities (true stress, true strain), it is assumed that the material is incompressible and isotropic, and the deformation is supposed to be homogeneous. The extensometer allows to measure the displacement $\Delta \mathrm{L}$ and by knowing the initial height of the sample $\mathrm{L}_{0}$, the true axial strain is obtained from the following expression:

$$
\varepsilon_{z z}=\operatorname{Ln}\left(1+\frac{\Delta L}{L_{0}}\right)
$$

The true stress becomes: 


$$
\sigma_{z z}=\sigma_{N} \cdot\left(1+\frac{\Delta L}{L_{0}}\right)
$$

where $\sigma_{N}=F / S_{0}$, is the nominal stress and $\mathrm{S}_{0}$ is the initial section.

Fig. 2 shows the axial stress-strain curves resulting from the tests at different temperatures and a speed of $10^{-3} \mathrm{~s}^{-1}$. From this graph, we can notice that the stress level decreases when the temperature increases. In addition, the curves confirm the very marked nonlinearity of the PMMA behavior, and a weak softening followed by a noticeably observed hardening.

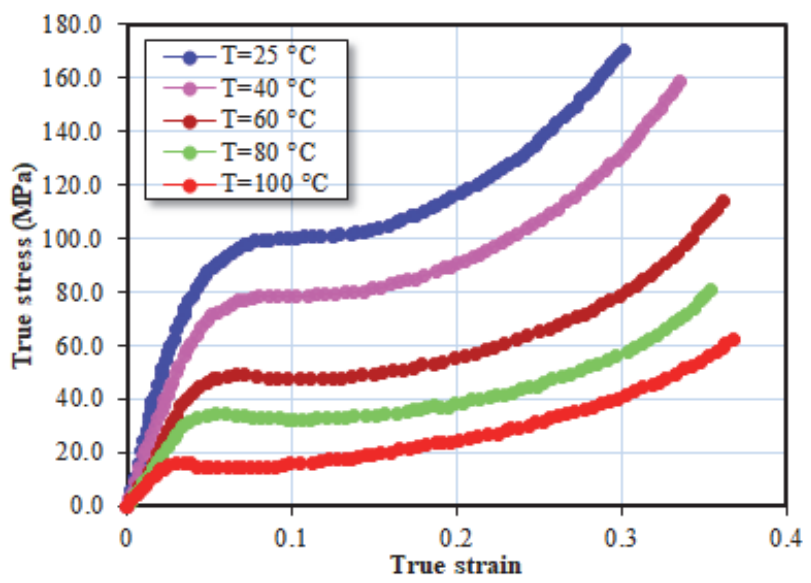

Figure 2: True axial stress-strain curves at different temperatures and a strain rate of $10^{-3} \mathrm{~s}^{-1}$ on a PMMA samples.

By plotting on a graph the evolution of the stress as a function of the deformation (Fig. 3), for different strain rates, and for the same temperature, we have been able to highlight the dependence of PMMA behavior on strain rate. These curves show that the elastic limit, the Young's modulus, and the hardening decreases with the decrease of the strain rate. The curves show a peak which is slightly pronounced at room temperature and becomes more significant with the increase of the temperature.

\section{PARAMETERS IDENTIFICATION AND VALIDATION OF THE MODEL}

he identification of viscoplastic parameters for PMMA goes through the classical process using linear least squares regression from PMMA strain-strain curves at different strain rates. We draw the following function:

$$
\operatorname{Ln} \mathrm{D}^{v p}=f\left(\gamma\left(\frac{\sigma}{\sigma_{0}}-1\right)^{\frac{1}{m}}\right)
$$

For the three strain rate values $10^{-4}, 10^{-3}$, and $10^{-2} \mathrm{~s}^{-1}$, this evolution is a linear function $y=a \cdot x+b$ which allows us to determine the coefficients $a$ and $b$. Finally the parameters are deduced as follows:

$$
\gamma=\operatorname{Exp}(b), m=1 / a
$$

The values of the parameters obtained for each temperature are given in Tab. 2. 


\begin{tabular}{cccc}
\hline Parameter & $\mathrm{T}=25^{\circ} \mathrm{C}$ & $\mathrm{T}=60^{\circ} \mathrm{C}$ & $\mathrm{T}=80^{\circ} \mathrm{C}$ \\
$\mathrm{E}(\mathrm{MPa})$ & 2565 & 1084 & 833 \\
$v$ & 0.32 & 0.33 & 0.33 \\
$\mathrm{~m}$ & 0.346 & 0.294 & 0.295 \\
$\gamma$ & 0.027 & 0.0137 & 0.0298 \\
$\sigma_{0}(\mathrm{MPa})$ & 89 & 40 & 29 \\
\hline
\end{tabular}

Table 2: Material parameters of elastic-viscoplastic model for PMMA at different temperatures.

To validate the viscoplastic model, we simulated compression tests performed on PMMA sample at different strain rates and at study temperatures $\left\{\mathrm{T}=25,60\right.$ and $\left.80^{\circ} \mathrm{C}\right\}$.

We have examined the macroscopic behavior of PMMA with the set of parameters reported in Tab. 2 . As can be seen in Fig. 3, there is an acceptable agreement between experimental data and simulation results.

For high strain rates and at $25^{\circ} \mathrm{C}$ and $80^{\circ} \mathrm{C}$, the predicted flow yield is near to the experimental measurements, but the hardening deviates from it. This difference can be explained by the experimental calculation of the stresses from a rectangular surface, whereas the sample has a barrel shape with a section which changes and becomes more important in the middle.

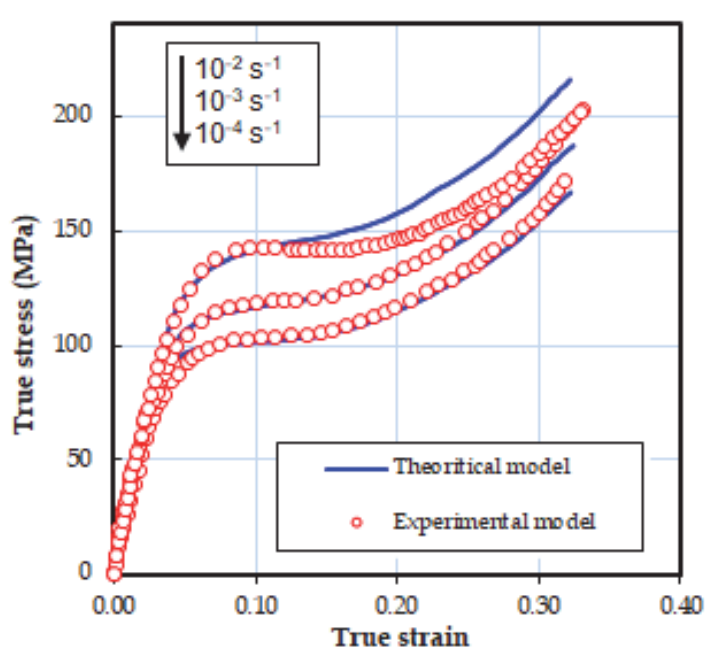

(a) $\mathrm{T}=25^{\circ} \mathrm{C}$

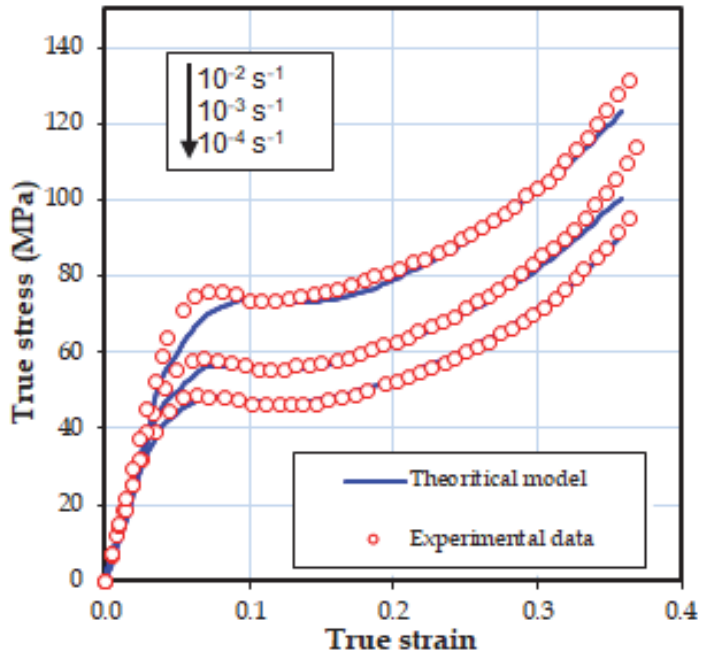

(b) $\mathrm{T}=60^{\circ} \mathrm{C}$

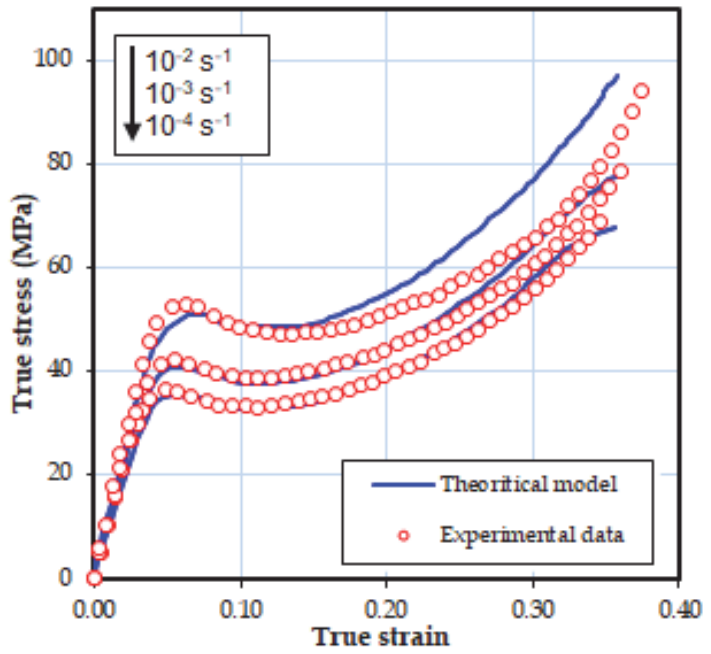

(c) $80^{\circ} \mathrm{C}$

Figure 3: Stress-strain curves of the PMMA for different strain rates and at temperatures of: (a) $25^{\circ} \mathrm{C}$, (b) $60^{\circ} \mathrm{C}$ and (c) $80^{\circ} \mathrm{C}$. 


\section{SIMULATION OF THE HPT PROCESS}

he simulations were performed by the finite element code MSC.Marc using eight (8) nodes hexahedral elements. The initial dimensions of the PMMA samples used are $20 \mathrm{~mm}$ in diameter and $10 \mathrm{~mm}$ in thickness. It should be noted that the mesh size selected is largely sufficient to show accurately the distribution of localized plastic strain within the samples. The upper and lower anvils were considered as rigid bodies in the finite element simulations. The upper anvil is subjected to an imposed displacement of compression, while the lower anvil is subjected to rotation. The effects of the hydrostatic pressure applied and the torsion angle on the evolution of the equivalent plastic strain were highlighted in this numerical investigation of PMMA behavior during HPT process.

\section{Effect of the bydrostatic pressure}

To highlight the effect of hydrostatic compression, four different vertical displacements were imposed by the upper anvil. A constant rotation speed of $0.2618 \mathrm{rad} / \mathrm{sec}$ was applied during the torsion. The results obtained for the evolution of the equivalent plastic strain along the radial distance from the center for various imposed compression displacements combined with a $30^{\circ}$ of torsion angle are illustrated in Fig. 4. It may be noted that the equivalent plastic strain increases with the increase of the imposed compressive displacement. In addition, it can be seen that the influence of this parameter becomes significant by moving away from the center of the specimen and likewise for the heterogeneity of the plastic strain distribution. Indeed, for an imposed displacement of $1 \mathrm{~mm}$, an equivalent plastic strain $\left(\varepsilon_{p}\right)$ of 1.49 was obtained, whereas, for the one of $2.5 \mathrm{~mm}$, $\varepsilon_{p}=1.91$.

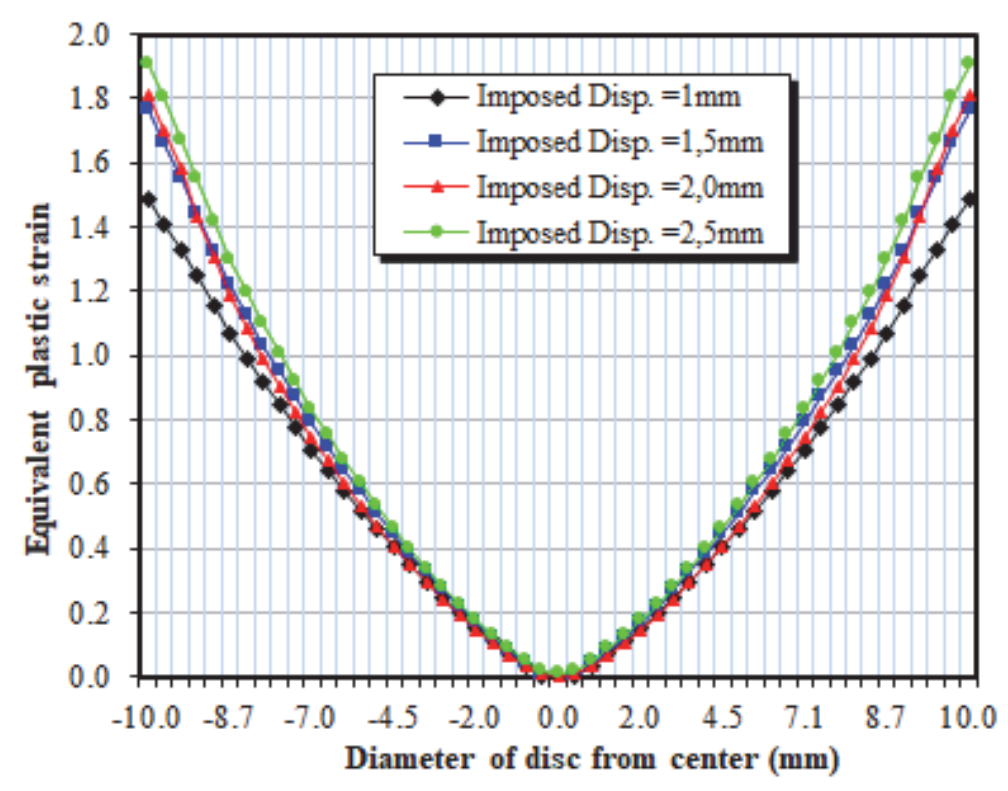

Figure 4: Distribution of the equivalent plastic strain along the radial distance of the disk for different imposed vertical displacements.

The distributions of the equivalent plastic strain in the deformed geometries of the sample at the end of the process for imposed displacements of $1 \mathrm{~mm}, 1.5 \mathrm{~mm}, 2 \mathrm{~mm}$ and $2.5 \mathrm{~mm}$ are illustrated in Fig. 5. It can be noted that the highest deformation values are located in the lower and upper regions of the sample. Therefore, in order to improve the level of the plastic strain distribution, it is necessary to increase the torsion angle. Furthermore, it should be interesting to remember that the decrease of the sample thickness contributes also to the increase of the plastic strain as it has been highlighted by Drai and Aour [42].

\section{Effect of torsion angle}

In order to illustrate the effect of torsion angle on the evolution of equivalent plastic strain a vertical displacement of $1 \mathrm{~mm}$ was imposed by the upper anvil on the sample and was maintained during the torsion with different angles of the lower anvil $\left(15^{\circ}, 30^{\circ}, 45^{\circ}\right.$ and $\left.60^{\circ}\right)$. The simulations were performed with low angular velocity of $0.26 \mathrm{rad} / \mathrm{sec}$ in order to conduct the process in isothermal conditions. 

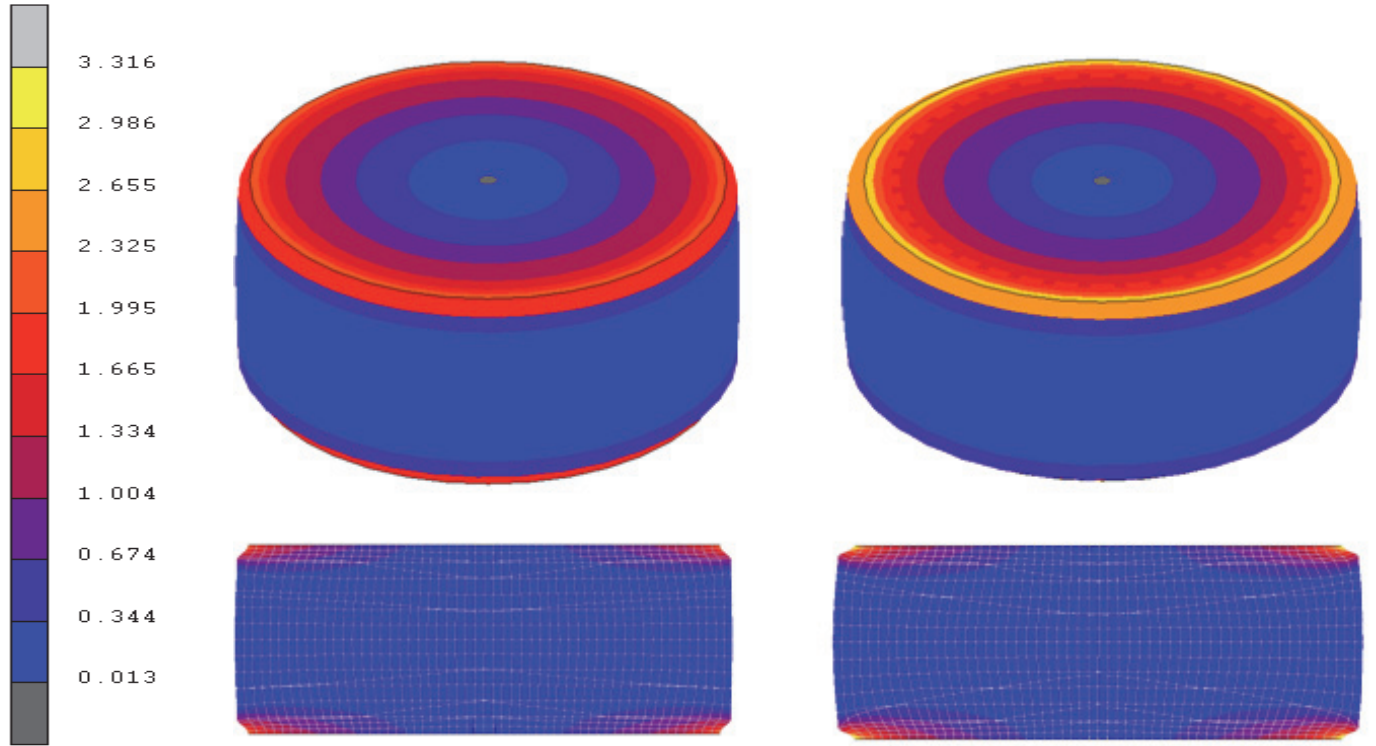

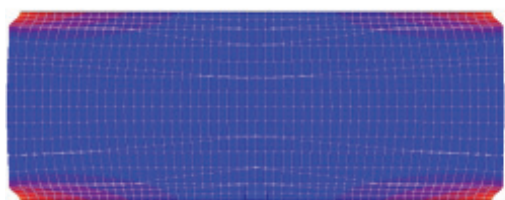

(a)
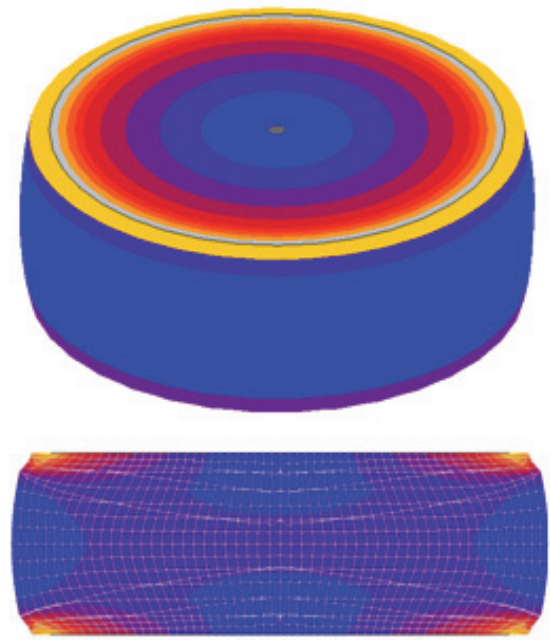

(c)

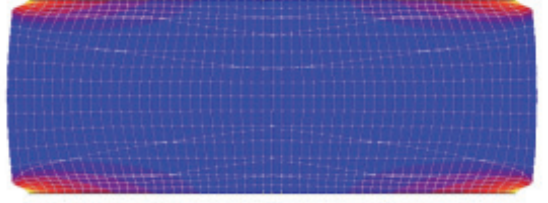

(b)

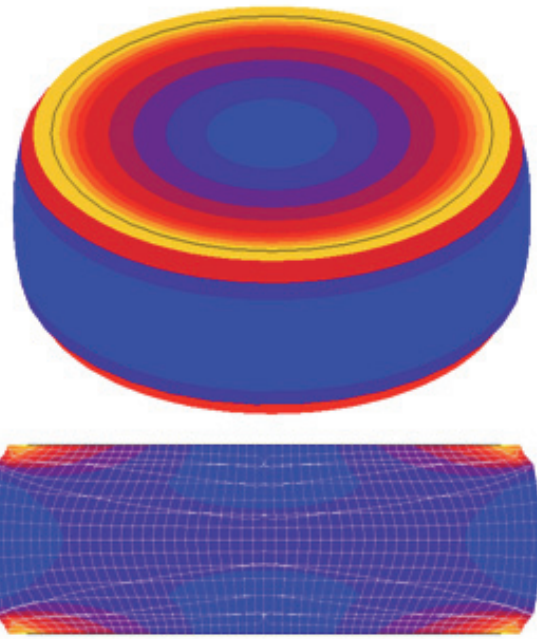

(d)

Figure 5: Distribution of the equivalent plastic strain as a function of the imposed displacements on the deformed PMMA sample at the end of HPT process in the case of: (a) $1 \mathrm{~mm}$, (b) $1.5 \mathrm{~mm}$, (c) $2 \mathrm{~mm}$ and (d) $2.5 \mathrm{~mm}$.

\section{Evolution of equivalent plastic strain}

Fig. 6 shows the distribution of the equivalent plastic strain along the sample radius for an imposed displacement of 1 mm and different torsion angles. It can be observed that the accumulated plastic deformation increases with the increase of the torsion angle and becomes very important at the edge of the sample.

Fig. 7 illustrates the isovalue contours of the equivalent plastic strain distribution in the PMMA samples deformed during the HPT process, in the case of $1 \mathrm{~mm}$ imposed displacement and a torsion angle of: (a) $15^{\circ}$, (b) $30^{\circ}$, (c) $45^{\circ}$ and (d) $60^{\circ}$.

From Fig. 8, it can be observed that after the vertical compressive displacement of $1 \mathrm{~mm}$ the plastic strain is very low and its maximum value does not exceed 0.3 . In addition, at this stage, the plastic strain induced by a simple compression remains very low especially in the middle of the sample. However, after the application of torsion under high pressure, the plastic strain increases with the increase of the torsion angle $\theta$ and becomes very high in the upper and lower areas, where it reaches a maximum value of 4.72 when $\theta=60^{\circ}$. On the other hand, in the center it is always weak. Therefore, it is advised to use small 
thicknesses in the case of PMMA samples, to obtain a good homogeneity and a large plastic strain in the sample processed by HPT.

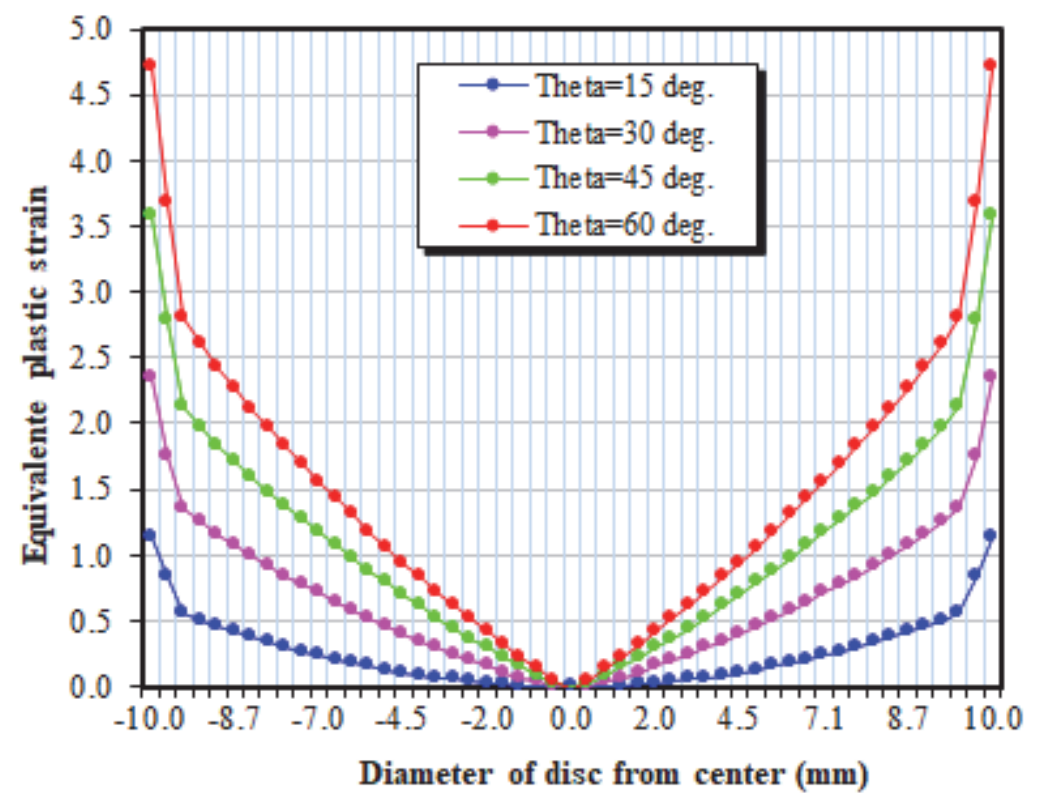

Figure 6: Evolution of the equivalent plastic strain as a function of the radial distance for different torsion angles at the end of HPT process.

\section{Evolution of the mean normal stress}

In order to study the state of the stresses in the PMMA sample, the distributions of mean normal stresses along the diameter of the upper face at the end of HPT process using an imposed compressive displacement of $1 \mathrm{~mm}$ of compression with different torsion angles are presented in Fig. 9. It can be seen that as the torsion angle increases, the compression stress increases at the central portion of the upper surface of the sample.
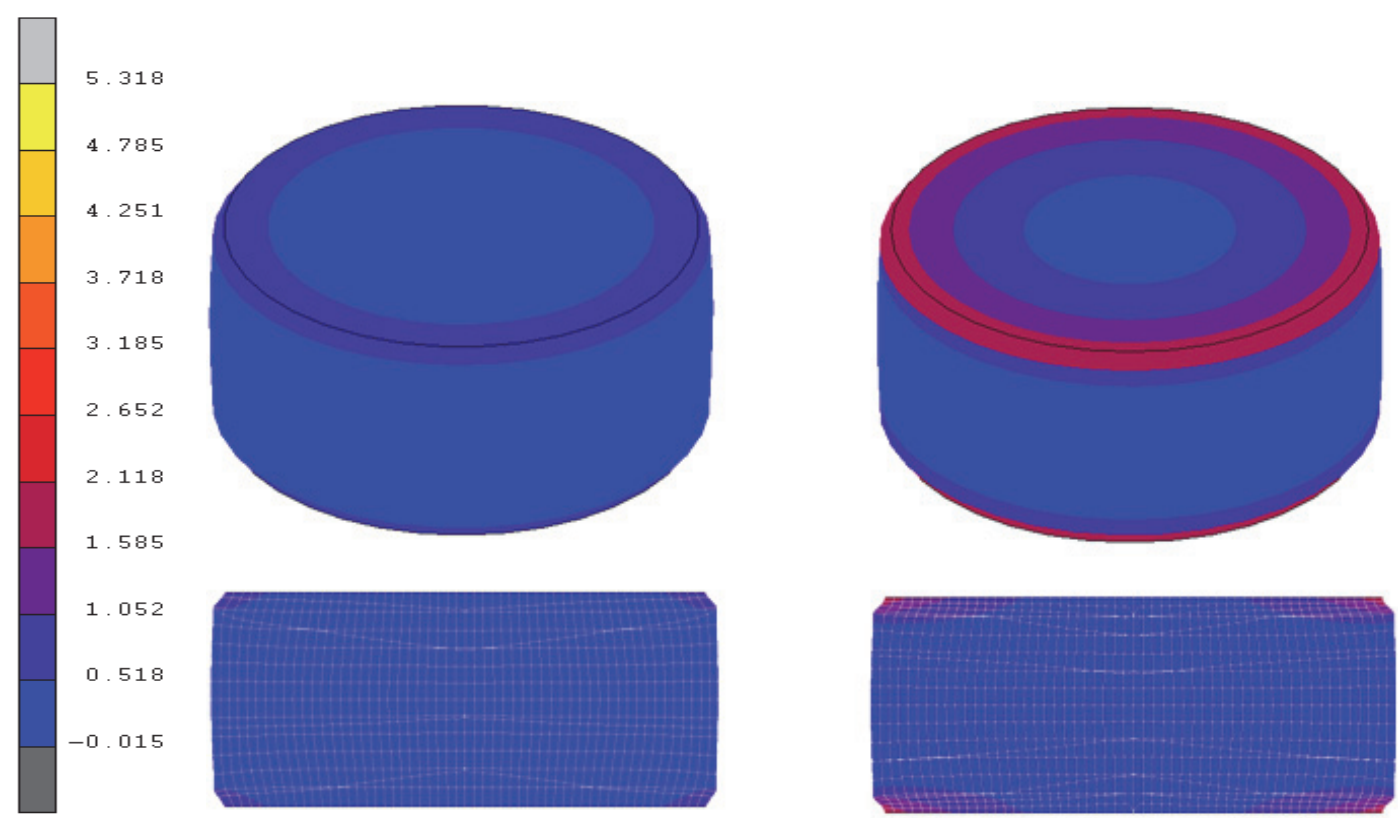

(a)

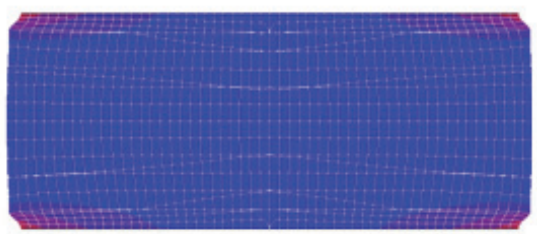

(b) 

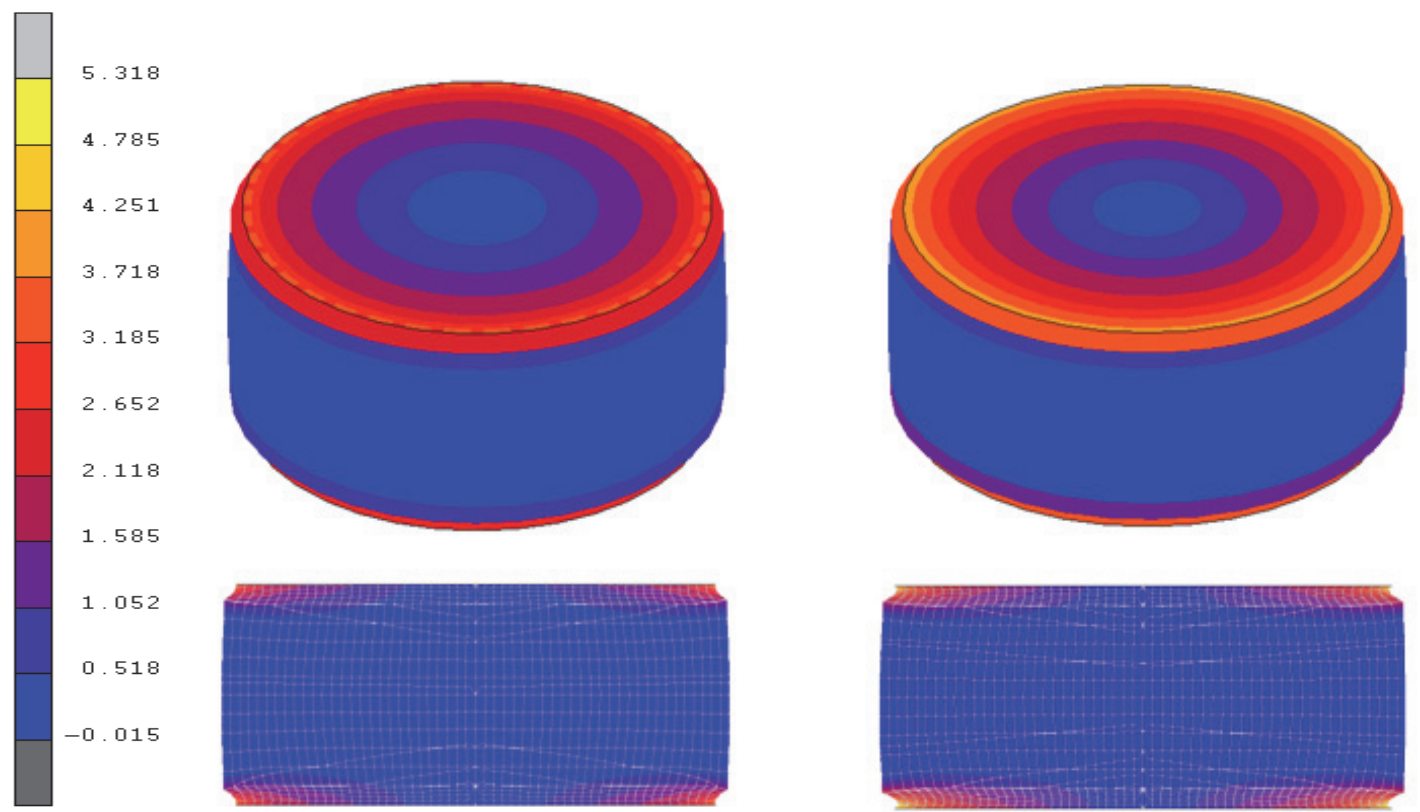

(c)

(d)

Figure 7: Distribution of the equivalent plastic strain in the deformed sample during HPT process in the case of an imposed compressive displacement of $1 \mathrm{~mm}$ with a torsion angle of: (a) $15^{\circ}$, (b) $30^{\circ}$, (c) $45^{\circ}$ and (d) $60^{\circ}$.

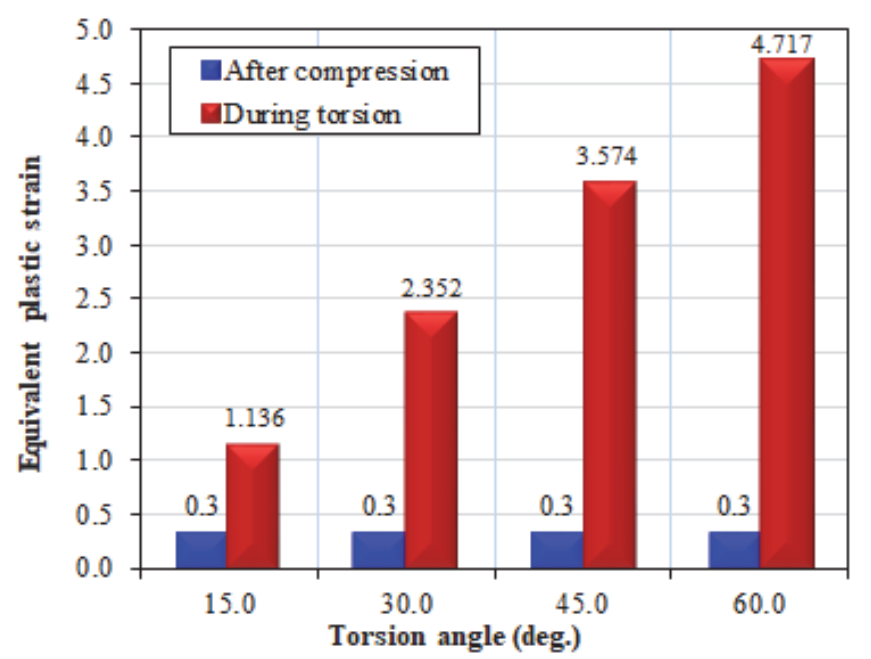

Figure 8: Evolution of the equivalent plastic strain at the beginning and the end of torsion during HPT process at the upper area of the sample.

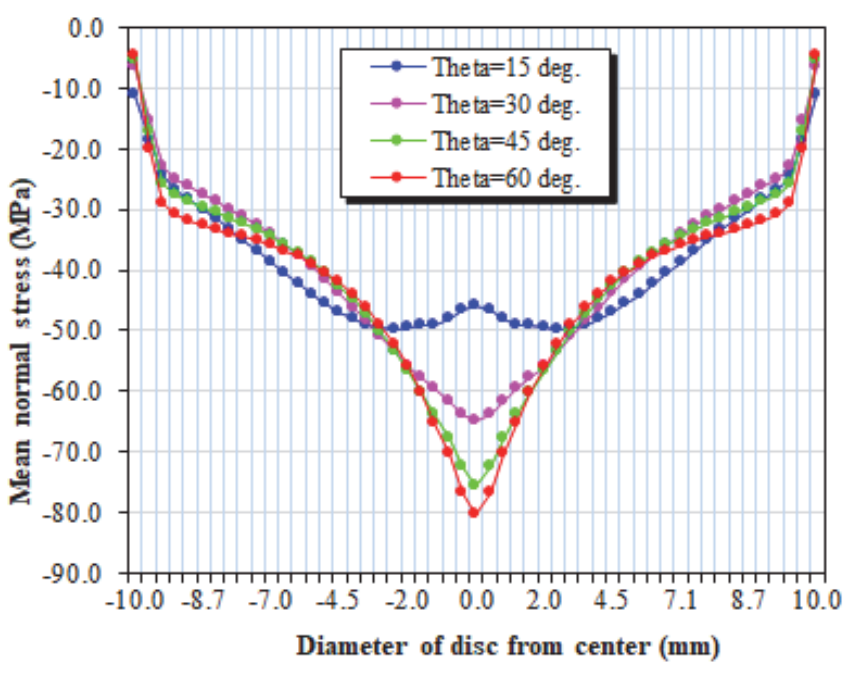

Figure 9: Evolution of the average normal stress along the diameter of the upper face at the end of HPT process using a compressive displacement of $1 \mathrm{~mm}$ with different torsion angles.

Fig. 10 illustrates the contours plots of the mean normal stress distribution in the PMMA sample deformed during HPT process. It can be observed that the central part of the sample is stressed in compression, however the peripheral region (in yellow color) is under tensile stress and this zone increases with the increase of the torsion angle. This explains the heterogeneity of the equivalent plastic strain distribution. In addition, the maximum value is always located in the central part of the sample-anvil interfaces for the four torsion angles.

\section{Effect of temperature}

From the macroscopic point of view, the behavior of PMMA is highly dependent on temperature. It is the site of behavioural transitions that can be associated with different molecular relaxations. It is the site of behavioral transitions that can be associated with different molecular relaxations, i.e. activation of changes in local conformations, resulting in the most brutal behavior changes in certain temperature ranges. To study the dependence of PMMA behavior during HPT process under 
the effect of temperature, a series of numerical calculations was carried out for three different temperatures $T=\{25,60$ and $80^{\circ} \mathrm{C}$ \}. Noting that the same constitutive law described in the previous paragraph has been identified at different temperatures under isothermal conditions and the material parameters obtained are presented in Tab. 2. The same operating conditions previously used (compression of $1 \mathrm{~mm}$ with a torsion angle of $15^{\circ}$ ) were applied for the simulation of the HPT process under different temperatures.
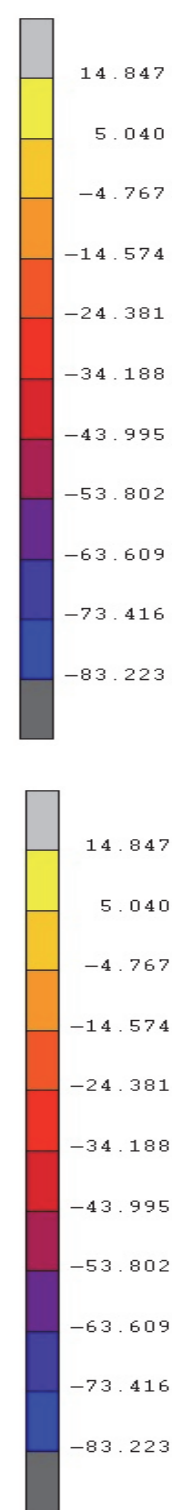

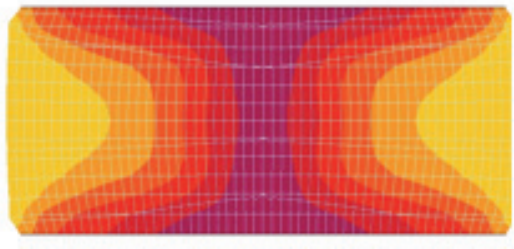

(a)
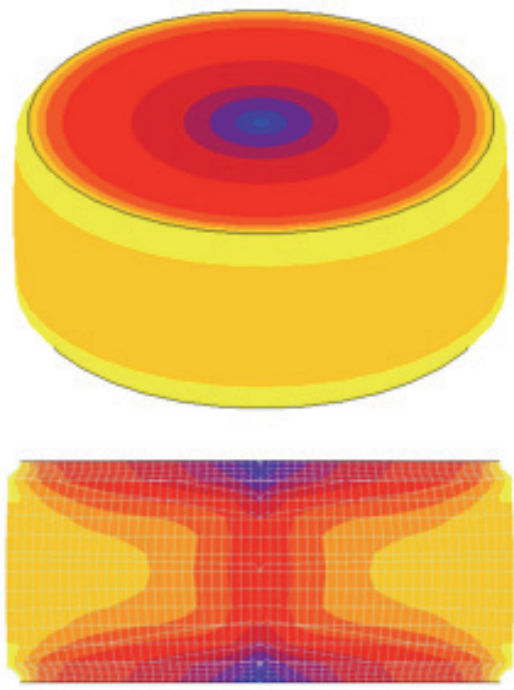

(c)
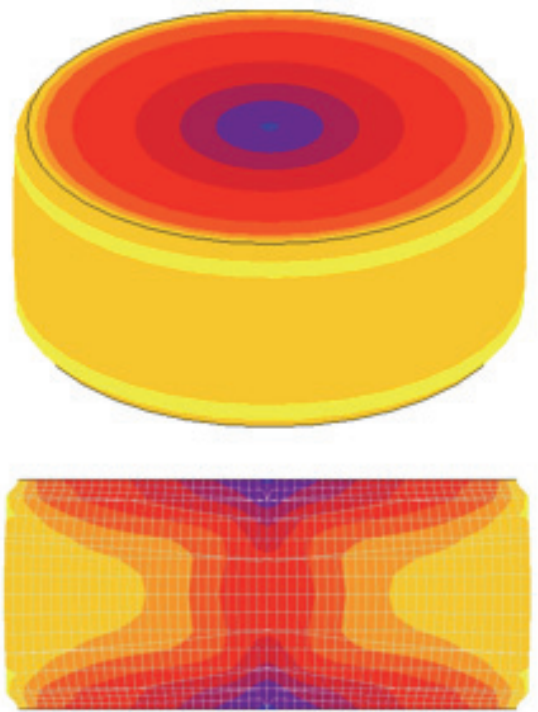

(b)
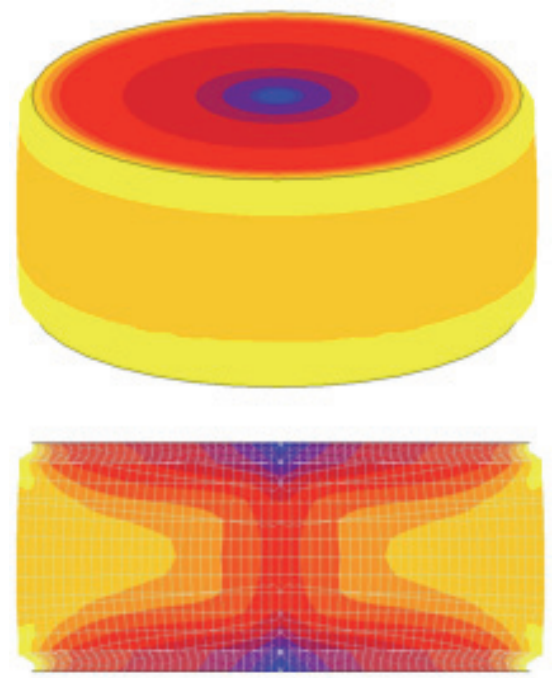

(d)

Figure 10: Distribution of the average normal stress in the deformed sample during HPT process in the case of a $1 \mathrm{~mm}$ of compression with a torsion angle of: (a) $15^{\circ}$, (b) $30^{\circ}$, (c) $45^{\circ}$ and (d) $60^{\circ}$.

\section{Distribution of the equivalent plastic strain}

In order to highlight the distribution of the plastic deformation in the PMMA sample, the iso-value contours of this latter at the end of the process for three different temperatures are presented in Fig. 11. It can be noted that the temperature has a slight influence on the magnitude of the plastic deformation during HPT process. 

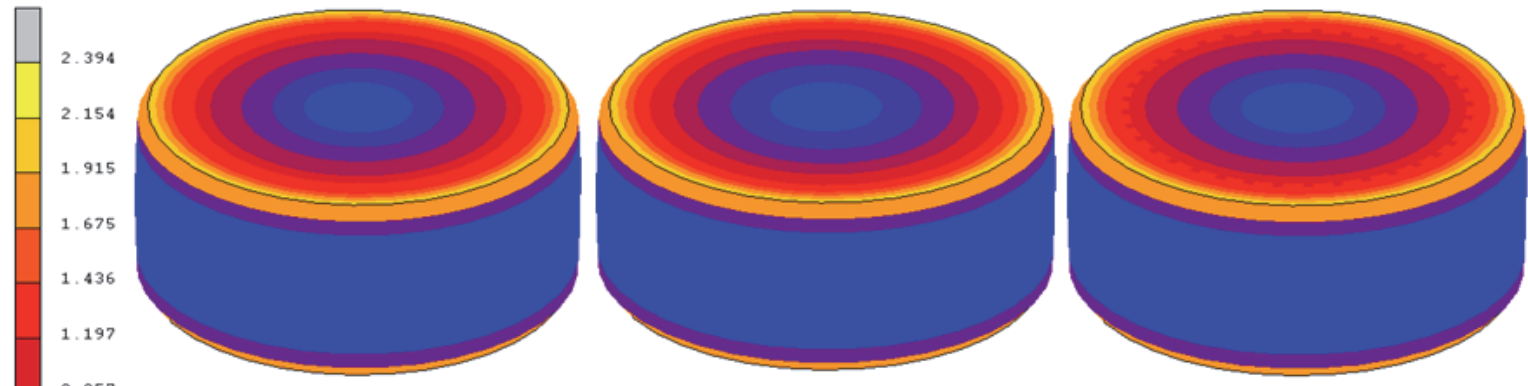

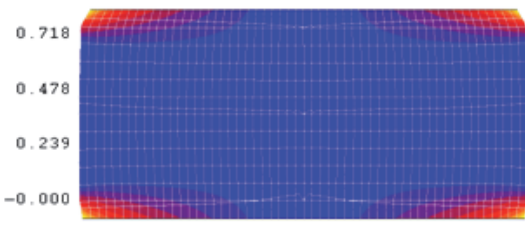

(a)

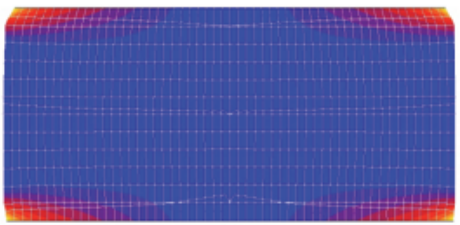

(b)

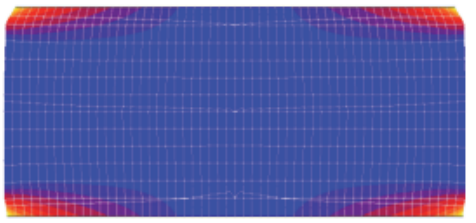

(c)

Figure 11: Distribution of the equivalent plastic strain in the deformed sample with a compression of $1 \mathrm{~mm}$ and a torsion angle of $15^{\circ}$ for different temperatures: (a) $25^{\circ} \mathrm{C}$, (b) $60^{\circ} \mathrm{C}$ and (c) $80^{\circ} \mathrm{C}$.

This slight influence of temperature can be confirmed by plotting the distribution of the equivalent plastic strain along the radial distance from the upper surface of the sample as shown in Fig. 12. A slight difference was found. In addition, the maximum value of equivalent plastic strain is approximately 2.36 .

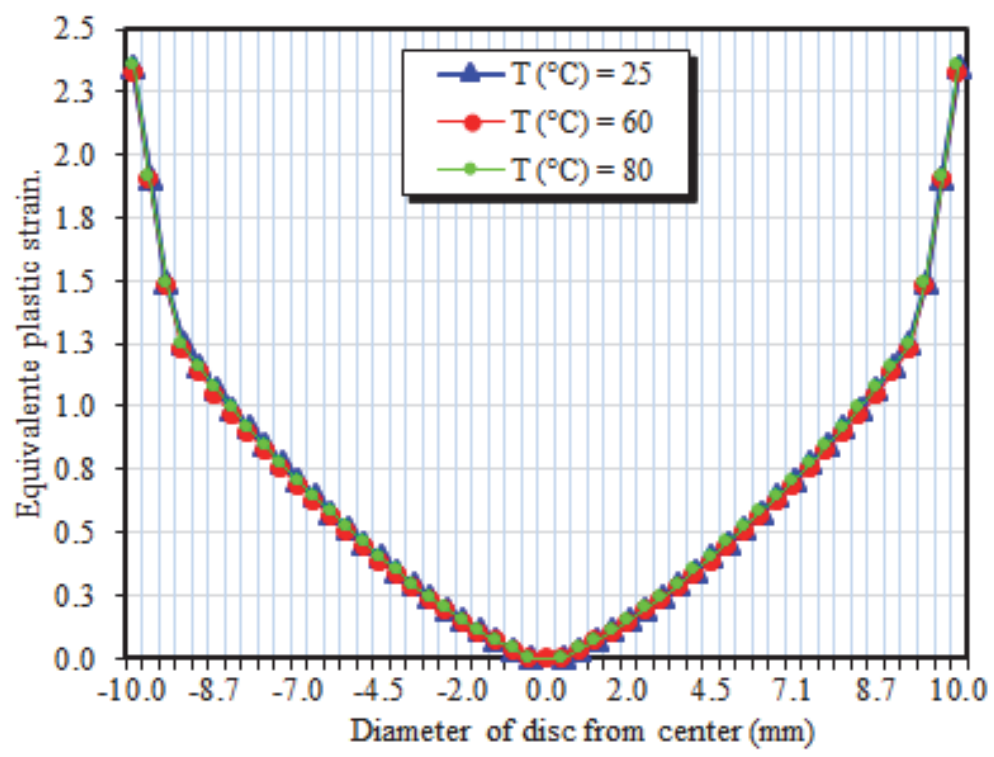

Figure 12: Distribution of the equivalent plastic strain as a function of the radial distance in the upper surface of the sample during the HPT process for different temperatures: $25^{\circ} \mathrm{C}, 60^{\circ} \mathrm{C}$ and $80^{\circ} \mathrm{C}$.

\section{Evolution of applied load and torque}

Fig. 13 shows the simulation results for the evolution of the compression load applied by the upper anvil as a function of the time during HPT process at various temperatures. The load required for each temperature in the ascending order $\left(25^{\circ} \mathrm{C}\right.$, $60^{\circ} \mathrm{C}$ and $80^{\circ} \mathrm{C}$ ) is respectively 11800,16200 and $36000 \mathrm{~N}$. We can see that when the temperature increases, the load required for HPT process decreases. For example, for a temperature of $25^{\circ} \mathrm{C}$, the required load is more than three times of that required at room temperature. Moreover, the load versus time evolution during the HPT process can be subdivided into four main stages. The first stage starts from the origin up to the end of compression phase. This stage corresponds to the elastic deformation of compression. The second stage corresponds to the increase of the load from the elastic limit of 
compression to the maximum value of the load. This stage corresponds to initiation and propagation of the plastic zone between the two upper and lower surfaces of the sample. The maximum force corresponds to the formation of the shear band along the cross-section of the sample, which precedes softening. The third stage corresponds to the decrease of the load from the peak to a minimum and is characterized by the initiation of the plastic flow. Beyond (stage 4), the load remains almost constant. This stage corresponds to the steady-state of the plastic flow when the plastic strain reaches its saturation value.

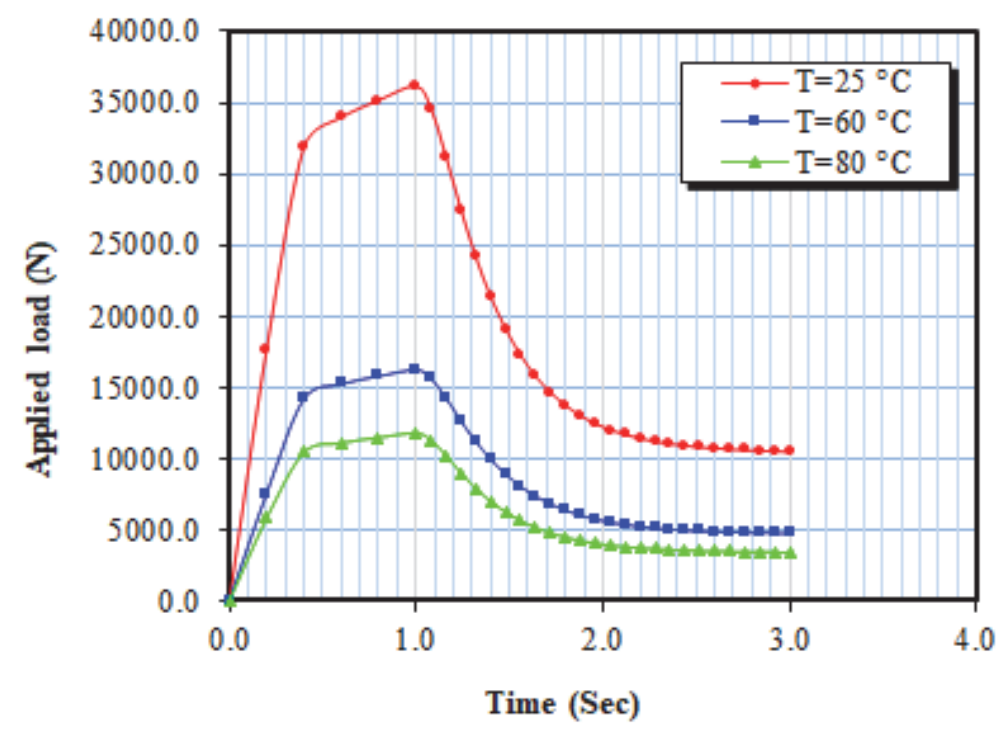

Figure 13: Evolution of the compression load applied by the upper anvil as a function of the time of HPT process for different temperatures.

Fig. 14 shows the actual values obtained by numerical simulation of the torque required for torsion phase of HPT process when it carried out at different temperatures $\left(25^{\circ} \mathrm{C}, 60^{\circ} \mathrm{C}\right.$ and $\left.80^{\circ} \mathrm{C}\right)$. It can be noticed that there is an abrupt increase from the torsion phase followed by a plateau (a horizontal line) after about $1.8 \mathrm{sec}$. This aspect can be attributed to the plastic flow in the direction of rotation (when the elastic limit due to the torsion is exceeded). It should be noted that the conduct of the process with a temperature higher than room temperature and lower than the glass transition temperature of the PMMA allows to reduce the pressure and the torque required for the deformation of the sample during HPT process.

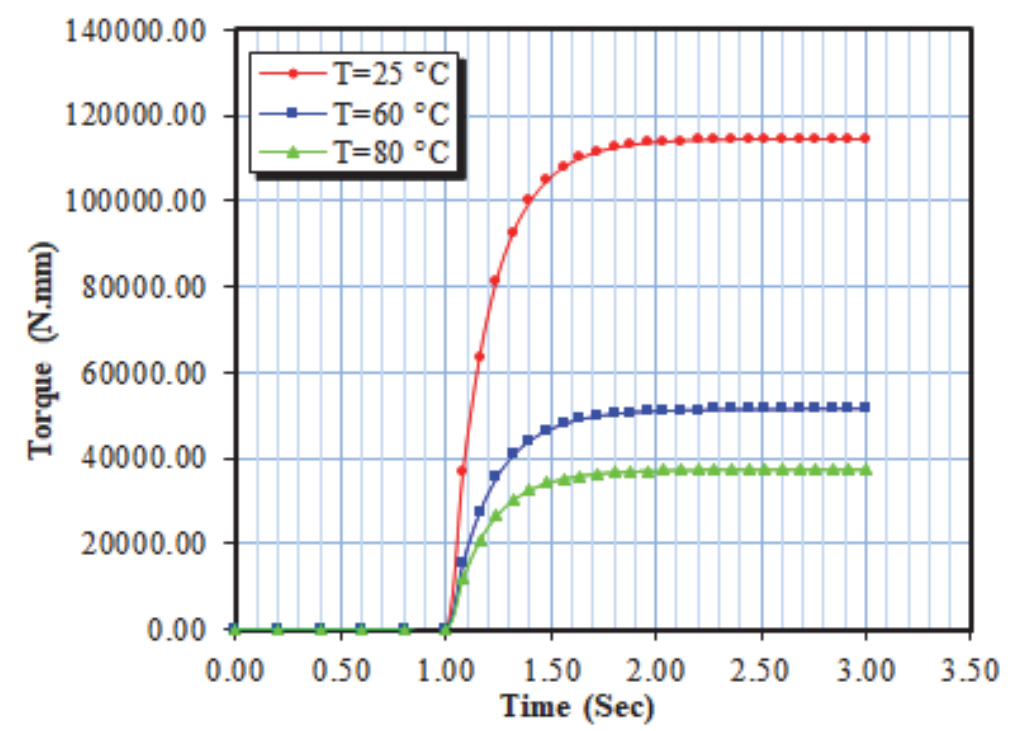

Figure 14: Evolution of the torque as a function of time process for different temperatures. 
Three particular properties can be highlighted when the sample is deformed at high temperatures: (a) reduced plastic strain distribution in the sample, (b) decrease of the required load and (c) decrease of the required torque. Furthermore, strain recovery during the cooling stage may affect the process. This point will be the subject of further mechanical and microstructural investigations.

\section{CONCLUSION}

7 he aim of this work is devoted to study the applicability of HPT process for a typical amorphous polymer which is polymethyl-methacrylate (PMMA). For this purpose, an identification of the parameters of a Perzyna elastoviscoplastic phenomenological model was performed using compression tests at different temperatures and strain rates. After the identification of the parameters, a numerical investigation was carried out to highlight the effects of the main processing parameters in the case of an imposed compressive displacement and different torsion angles. From the results obtained, we can draw the following conclusions:

- The equivalent plastic strain increases with the increase of the imposed compression displacement.

- Accumulated plastic deformation increases with the increase of torsion angle and becomes very important at the edge of the sample.

- It is advised to use small thicknesses to obtain a good homogeneity of the plastic deformation.

- The temperature has a slight effect on the evolution of the plastic deformation. However, it can be used to reduce the force and torque required for HPT process if necessary.

\section{ACKNOWLEDGMENTS}

7 his research was supported by the General Directorate of Scientific Research and Technological Development (DGRSDT : Direction Générale de la Recherche Scientifique et du Développement Technologique) of Algeria. The authors gratefully acknowledge the scientific support of the two research teams from the Lille Mechanics Unit (France) and the Laboratory of Applied Biomechanics And Biomaterials (LABAB) of Oran (Algeria).

\section{REFERENCES}

[1] Alhajeri, S.N., Khaled, J., Al-Fadhalah, A., Almazrouee, I. and Langdon, T.G. (2016). Microstructure and microhardness of an Al-6061metal matrix composite processed by high-pressure torsion, Mater. Charact. , 118, pp. 270-278.

DOI: 10.1016/j.matchar.2016.06.003.

[2] Beloshenk, V., Vozniak, Iu., Beygelzimer, Y., Estrin, Y. and Kulagin, R. (2019). Severe Plastic Deformation of Polymers, Mater. Trans., 60(7), pp. 1192-1202. DOI: 10.2320/matertrans.MF201912

[3] Um, H.Y., Park, B.H., Ahn, D.H., AbdElAal, M.I., Park, J., Kim, H.S. (2017). Mechanical and biological behavior of ultrafine-grained Ti alloy aneurysm clip processed using high-pressure torsion, J. Mech. Behav. Biomed. Mater. , 68, pp. 203-209. DOI: 10.1016/j.jmbbm.2017.02.002.

[4] Peitang, W., Cheng, L., Kiet T., Lihong, S., Guanyu, D., and Wenbin, H. (2017). A study on the texture evolution mechanism of nickel single crystal deformed by high pressure torsion, Mater. Sci. Eng. A, 684, pp. 239-248. DOI: 10.1016/j.msea.2016.11.098.

[5] Yu, I., Kulagin, R., Fedorov, V., Mazilkin, A., Scherer, T., Baretzky, B. and Hahn, H. (2016). High Pressure Torsion Extrusion as a new severe plastic deformation process, Mater. Sci. Eng. A, 664, pp. 247-256. DOI: 10.1016/j.msea.2016.04.008.

[6] Figueiredo, R.B., Pereira, P.H.R., Aguilar, M.T.P., Cetlin, P.R. and Langdon, T.G. (2012). Using finite element modeling to examine the temperature distribution in quasi-constrained high-pressure torsion, Acta Mater., 60, pp. 3190-3198. DOI: 10.1016/j.actamat.2012.02.027.

[7] Valiev, R.Z., Song, C., McFadden, S.X., Mukherjee, A.K. and Mishra, R.S. (2001). TEM/HREM observations of nanostructured superplastic Ni 3 Al, Philos. Mag. A, 81, pp. 25-36. DOI: 10.1007/s10853-014-8204-5. 
[8] Xu, C., Dobatkin, S.V., Horita, Z. and Langdon, T.G. (2009). Superplastic flow in a nanostructured aluminum alloy produced using high-pressure torsion, Mater. Sci. Eng. A, 500, pp. 170-175. DOI: 10.1016/j.msea.2008.09.049.

[9] Harai, Y., Edalati, K., Horita, Z., and Langdon, T.G. (2009). Using ring samples to evaluate the processing characteristics in high-pressure torsion, Acta Mater., 57, pp. 1147-1153. DOI: 10.1016/j.actamat.2008.10.046.

[10] Edalati, K., Horita, Z., Furuta, T. and Kuramoto, S. (2013). Dynamic recrystallization and recovery during high-pressure torsion: Experimental evidence by torque measurement using ring specimens, Mater. Sci. Eng. A, 559, pp. 506-509. DOI: $10.1016 /$ j.msea.2012.08.132.

[11] Horita, Z. and Langdon, T.G. (2008). Achieving exceptional superplasticity in a bulk aluminum alloy processed by highpressure torsion, Scr.Mater., 58, pp. 1029-1032. DOI: 10.1016/j.scriptamat.2008.01.043.

[12] Faraji, G., Kim, H.S., and Kashi, H.T. (2018). Severe Plastic Deformation Methods for Bulk Samples, Book chapter: Severe Plastic Deformation, pp. 37-112. DOI: 10.1016/B978-0-12-813518-1.00002-3.

[13] Ivanisenko, Y., Kulagin, R., Fedorov, V., Mazilkin, A., Scherer, T., Baretzky, B. and Hahn, H. (2016). High Pressure Torsion Extrusion as a new severe plastic deformation process, Mater. Sci. Eng. A, 664, pp. 247-256. DOI: $10.1016 /$ j.msea.2016.04.008.

[14]Zhilyaev, A.P., and Langdon, T.G. (2008). Using high-pressure torsion for metal processing: Fundamentals and applications, Prog. Mater. Sci., 53, pp. 893-979. DOI: 10.1016/j.pmatsci.2008.03.002.

[15] Lee, D.J., Yoon, E.Y., Ahn, D.H., Park, B.H., Park, H.W., Park, L.J., Estrin, Y. and Kim, H.S. (2014). Dislocation density-based finite element analysis of large strain deformation behavior of copper under high-pressure torsion, Acta Mater., 76, pp. 281-293. DOI: 10.1016/j.actamat.2014.05.027.

[16] Vafai, R., Toroghinejad, M.R. and Pippan, R. (2012). Evaluation of mechanical behavior of nano-grained $2024 \mathrm{Al}$ alloy during high pressure torsion (HPT) process at various temperatures, Mater. Sci. Eng. A, 536, pp. 73-81.

DOI: $10.1016 /$ j.msea.2011.12.064.

[17] Peitang, W., Cheng, L., Kiet, T., Lihong, S.,Guanyu, D. and Wenbin, H. (2017). A study on the texture evolution mechanism of nickel single crystal deformed by high pressure torsion, Mater. Sci. Eng. A, 684, pp. 239-248. DOI: $10.1016 /$ j.msea.2016.11.098.

[18] Dimic, I., Cvijovic-Alagic, I., Volker B., Hohenwarter, A., Pippan, R., Veljovic, D., Rakin, M. and Bugarski, B. (2016). Microstructure and metallic ion release of pure titanium and $\mathrm{Ti}-13 \mathrm{Nb}-13 \mathrm{Zr}$ alloy processed by high pressure torsion, Mater Design., 91, pp. 340-347. DOI: 10.1016/j.matdes.2015.11.088.

[19] Draï, A. and Aour, B. (2013). Analysis of plastic deformation behavior of HDPE during high pressure torsion process, Eng. Struct., 46, pp. 87-93. DOI: 10.1016/j.engstruct.2012.06.033.

[20]Zhao, Y. and Zhang, J. (2007). Enhancement of yield strength in zirconium metal through high-pressure induced structural phase transition, Appl. Phys. Lett., 91, pp. 201907. DOI: 10.1063/1.2802726.

[21] Feng, B., Levitas, V.I. and Kamrani, M. (2018). Coupled strain induced alpha to omega phase transformation and plastic flow flow in zirconium under high pressure torsion in a rotational diamond anvil cell, Mater. Sci. Eng. A, 731, pp. 623633. DOI: $10.1016 /$ j.msea.2018.06.061.

[22] Seenuvasaperumal, P., Doi, K., Basha, D.A., Singh, A., Elayaperumal, A. and Tsuchiya, K. (2018). Wear behavior of HPT processed UFG AZ31B magnesium alloy, Mater Lett., 227, pp. 194-198. DOI: 10.1016/j.matlet.2018.05.076.

[23] Alhamidi, A., Edalati, K., Horita, Z., Hirosawa, S., Matsuda, K. and Terada, D. (2014). Softening by severe plastic deformation and hardening by annealing of aluminum-zinc alloy: Significance of elemental and spinodal decompositions, Mater. Sci. Eng. A, 610, pp. 17-27. DOI: 10.1016/j.msea.2014.05.026.

[24] Edalati, K., Matsuo, M., Emami, H., Itano, S., Alhamidi, A., Staykov, A., Smith, D.J., Orimo, S., Akiba, E. and Horita, Z. (2016). Impact of severe plastic deformation on microstructure and hydrogen storage of titanium-ironmanganese intermetallics, Script.Mater., 124, pp. 108-111. DOI: 10.1016/j.scriptamat.2016.07.007.

[25] Nikitina, M.A., R. Islamgaliev, K., and Sitdikov, V.D. (2016). Thermal stability of TiAl-based intermetallic alloys subjected to high pressure torsion, Mater. Sci. Eng. A, 651, pp. 306-310. DOI: 10.1016/j.msea.2015.10.121.

[26] Matsunoshita, H., Edalati, K., Furui, M., and Horita, Z. (2015). Ultrafine-grained magnesium-lithium alloy processed by high-pressure torsion: Low-temperature superplasticity and potential for hydroforming, Mater. Sci. Eng. A, 640, pp. 443-448. DOI: 10.1016/j.msea.2015.05.103.

[27] Edalati, K. and Horita, Z. (2016). A review on high-pressure torsion (HPT) from 1935 to 1988, Mater. Sci. Eng. A, 652, pp. 325-352. DOI: 10.1016/j.msea.2015.11.074.

[28] Figueiredo, R.B., Aguilar, M.T.P., Cetlin, P.R. and Langdon, T.G. (2012). Analysis of plastic flow during high-pressure torsion, J. Mater. Sci., 47, pp. 7807-7814. DOI: 10.1007/s10853-012-6506-z. 
[29] Wang, W., Song, Y., Gao, D., Yoon, E.Y., Lee, D.J., Lee, C. and Kim, H.S. (2013). Analysis of stress states in compression stage of high pressure torsion using slab analysis method and finite element method, Met. Mater. Int., 19, pp. 1021-1027. DOI: 10.1007/s12540-013-5014-2.

[30] Edalati, K., Miresmaeili, R., Horita, Z., Kanayam, H., and Pippan, R. (2011). Significance of temperature increase in processing by high-pressure torsion, Mater. Sci. Eng. A, 528, pp. 7301-7305. DOI: 10.1016/j.msea.2011.06.031.

[31] Pereira, P.H.R., Figueiredo, R.B., Huang, Y., Cetlin, P.R., and Langdon, T.G. (2014). Modeling the temperature rise in high-pressure torsion, Mater. Sci. Eng. A, 593, pp. 185-188. DOI: 10.1016/j.msea.2013.11.015.

[32] Kamrani, M., Levitas, V.I., and Feng, B. (2017). FEM simulation of large deformation of copper in the quasi-constrain high pressure-torsion setup, Mater. Sci. Eng. A, 705, pp. 219-230. DOI: 10.1016/j.msea.2017.08.078.

[33] Kulagin, R., Zhao, Y., Beygelzimer, Y., Toth, L.S. and Shtern, M. (2017). Modeling strain and density distributions during high-pressure torsion of pre-compacted powder materials, Mater. Res. Lett. 5, pp. 179-186. DOI: $10.1080 / 21663831.2016 .1241318$.

[34] Lee, D.J. and Kim, H.S. (2014). Finite element analysis for the geometry effect on strain inhomogeneity during high pressure torsion, J. Mater. Sci., 49, pp. 6620-6628. DOI: 10.1007/s10853-014-8283-3.

[35] Belayachi, N., Benseddiq, N. and Nait-Abdelaziz, M. (2008). Behavior of the heterogeneous glassy polymers: Computational modeling and experimental approach, Compos. Sci. Technol. 68, pp. 367-375. DOI: $10.1016 /$ j.compscitech.2007.07.002

[36] Perzyna, P. (1985). On Constitutive Modelling of Dissipative Solids for Plastic Flow, Instability and Fracture. In: A. Sawczuk (Eds), (1985), Plasticity Today-Modelling, Methods and Applications, pp. 657-679.

[37] Perzyna, P. (1966). Fundamental Problems in Viscoplasticity, In: Advances in Applied Mechanics, Academic press in New York., 9, pp. 243-377. DOI: 10.1016/S0065-2156(08)70009-7.

[38] Perzyna, P., and Pecherski, R. (1983). Modified theory of viscoplasticity. Physical foundations and identification of material functions for advanced strains, Arch. Mech., 35, pp. 423-436.

[39] Peric, D., Owen, D.R.J. and Honnor, M.E. (1992). A model for finite strain elasto-plasticity based on logarithmic strains: Computational Issues. Computer methods in applied mechanics and engineering, 94, pp. 35-61.

DOI: 10.1016/0045-7825(92)90156-E.

[40] Sluis, O.V.D., Schreurs, P.J.G, Brekelmans, W.A.M. and Meijer, H.E.H. (2000). Overall behavior of heterogeneous elastoviscoplastic materials: effect of microstructural modeling. Mech. Mat., 32, pp. 449-462. DOI: 10.1016/S0167-6636(00)00019-3.

[41] Sluis, O.V.D., Schreurs, P.J., and Meijer, H.E.H. (2001). Homogenisation of structured elastoviscoplastic solids at finite strains, Mech. Mat., 33, pp. 499-522. DOI: 10.1016/S0167-6636(01)00066-7.

[42] Drai, A. and Aour, B. (2017). Analysis of the temperature effect on the plastic strain of polymers during high pressure torsion (HPT) process, ICONTES2017: International Conference on Technology, Engineering and Science, October 26 - 29, 2017 Antalya/Turkey, The Eurasia Proceedings of Science, Technology, Engineering \& Mathematics (EPSTEM), 1, pp. 40-51. 